Etnográfica

Revista do Centro em Rede de Investigação em

Antropologia

vol. 17 (2) | 2013

Vol. 17 (2)

\title{
Alfred Métraux: antropologia aplicada e lusotropicalismo
}

Alfred Métraux: applied anthropology and lusotropicalism

\section{Lorenzo Macagno}

\section{(2) OpenEdition}

Journals

\section{Edição electrónica}

URL: https://journals.openedition.org/etnografica/3100

DOI: 10.4000/etnografica.3100

ISSN: 2182-2891

\section{Editora}

Centro em Rede de Investigação em Antropologia

\section{Edição impressa}

Data de publição: 1 junho 2013

Paginação: 217-239

ISSN: 0873-6561

\section{Refêrencia eletrónica}

Lorenzo Macagno, «Alfred Métraux: antropologia aplicada e lusotropicalismo», Etnográfica [Online], vol. 17 (2) | 2013, posto online no dia 19 junho 2013, consultado o 11 fevereiro 2022. URL: http:// journals.openedition.org/etnografica/3100 ; DOI: https://doi.org/10.4000/etnografica.3100

\section{(c) (1) (8)}

Etnográfica is licensed under a Creative Commons Attribution-NonCommercial 4.0 International License. 


\section{Alfred Métraux: antropologia aplicada e lusotropicalismo}

\section{Lorenzo Macagno}

O artigo explora um fragmento da longa trajetória de Alfred Métraux (1902-1963): sua relação ambígua com o legado intelectual de Gilberto Freyre. O locus desta relação se situa num momento específico da sua carreira, quando, no início da década de 1950, Métraux participa da coordenação do famoso projeto de pesquisa, promovido pela UNESCO, sobre "relações raciais" no Brasil. Métraux costumava se autodefinir como um etnógrafo e como um "homem de terreno". Mesmo confiando no papel que as ciências sociais deviam assumir na luta contra o racismo, em algumas circunstâncias chegou a expressar certo ceticismo diante da suposta eficácia da antropologia aplicada. Por outro lado, ciente da importância da pesquisa empírica, soube desconfiar da ideologia lusotropicalista e, portanto, das narrativas em torno da chamada "democracia racial". Contudo, seu diálogo com a antropologia cultural norte-americana o fez permanecer alerta diante da possibilidade de que as "relações raciais" no Brasil operassem no quadro de um "caráter nacional" singular e irredutível.

PALAVRAS-CHAVE: Alfred Métraux, antropologia aplicada, lusotropicalismo, Brasil.

Alfred Métraux: applied anthropology and lusotropicalism - This article explores a fragment of the long career of Alfred Métraux (1902-1963): his ambiguous relationship with the intellectual legacy of Gilberto Freyre. The locus of this relationship is situated in a specific period of his career, when at the beginning of the 1950s, Métraux participated in the coordination of the famous research project, promoted by UNESCO, on "race relations" in Brazil. Métraux generally defined himself as an ethnographer and "a fieldworker". Even though he trusted in the role that the social sciences should play in the struggle against racism, in some circumstances, he expressed a certain skepticism towards the supposed efficacy of applied anthropology. On the other hand, aware of the importance of empirical research, he had a certain distrust of the "lusotropicalist" ideology, and therefore, the narratives surrounding the so-called "racial democracy". However, his dialog with North American cultural anthropology caused him to remain alert to the possibility that "race relations" in Brazil operated in the arena of a singular and irreducible "national character".

KEYWORDS: Alfred Métraux, applied anthropology, lusotropicalism, Brazil.

MACAGNO, Lorenzo (lorenzom@ufpr.br) - Departamento de Antropologia, Universidade Federal do Paraná, Brasil. 
“[...] Un tel souci de la part de Métraux n'était pas seulement un souci de spécialiste avide de précision, mais un souci d'ordre proprement poétique: ne pas se contenter de décrire les choses mais, les ayant saisies dans toute leur réalité singulière, les faire vivre sous les yeux de celui qui vous lit" (Leiris 1964: 15).

DIFERENTEMENTE DE CLAUDE LÉVI-STRAUSS, ALFRED MÉTRAUX NÃO deixou para o repertório da antropologia uma "grande teoria". De qualquer maneira, seu legado etnográfico é inegável, mesmo que o seu lugar na história da disciplina permaneça, ainda, ambíguo. Ao que parece, na trajetória dos grandes antropólogos, a formulação de grandes dispositivos explicativos ou interpretativos é uma condição sine qua non no caminho para a definitiva consagração. Talvez essa constatação explique o fato de as contribuições de Métraux permanecerem, ainda, retratadas em "letra pequena" na história disciplinar. Contudo, seria um tanto arbitrário identificar uma causa unívoca que justifique esse suposto reconhecimento não plenamente consumado. Convenhamos, ademais, que a saída desse letargo não se encontra na simples construção de uma contrarresposta apologética, ou algo parecido, em torno à sua figura. Há, certamente, outros ingredientes - além do fato de não ter fundado nenhuma "escola" - que podem explicar esse lugar ambíguo: Métraux era, em alguma medida, uma espécie de "expatriado" (nascido na Suíça, criado na Argentina, formado na França, nacionalizado norte-americano...). Mas, ainda assim, a justificativa - atrelada a esse universo de referências "nacionais" múltiplas e difusas - não é suficiente. Sua trajetória e formação estão, sem dúvidas, estreitamente vinculadas a um importante período da institucionalização da antropologia francesa. Porém, no famoso Dictionnaire de l'ethnologie et de l'anthropologie (Dreyfus 1991), na entrada correspondente à "França", seu nome é praticamente ignorado. Outro elemento desconcertante se traduz no fato de que, apesar da sua indubitável contribuição à antropologia da América do Sul, ainda não apareceu - nesta parte do continente - uma iniciativa para traduzir, ao espanhol ou ao português, seus preciosos cadernos de notas e viagens. ${ }^{1}$ Seja como for, a própria figura complexa de Métraux - e as circunstâncias nas quais lhe tocou desenvolver seu trabalho - podem ajudar a explicar algumas destas aparentes incongruências. Sua trajetória desafia os lugares-comuns da historiografia da disciplina, empenhada, muitas vezes, em definir tradições nacionais, âmbitos de especialização e domínios geográficos específicos (americanistas, africanistas, melanesistas, brasilianistas) ou, simplesmente, genealogias teórico-metodológicas e campos intelectuais - e políticos - supostamente divergentes (etnologia versus antropologia social, e assim por diante). Em tal sentido,

l Trata-se do livro Itinéraires I, correspondente ao período 1935-1953 (Métraux 1978). Devido a uma série de impasses com a editora Payot, o volume Itinéraires 2 (1953-1961) nunca chegou a ser publicado, fora alguns textos avulsos divulgados pelo seu compilador André-Marcel d’Ans (1992). 
o "caso" Métraux nos obriga a relativizar essas etiquetas mais ou menos consagradas. Nestas páginas, pretendo explorar um fragmento do seu longo itinerário: a relação de Alfred Métraux com o legado de Gilberto Freyre (o "sociólogo" ou o "antropólogo", mas, também, o ideólogo). O locus desta relação não será necessariamente abordado aqui em termos de um vínculo intelectual pessoal, ou coisa parecida, senão em relação a uma espécie de matéria-prima que foi, por assim dizer, o ponto de partida obrigatório para uma reflexão intelectual sobre a sociedade brasileira da época: os debates - e combates - em torno à obra Gilberto Freyre. Mais especificamente, as coordenadas dessa relação serão, aqui, situadas num território delimitado: o do envolvimento de Alfred Métraux com o famoso projeto de pesquisa sobre "relações raciais" no Brasil promovido pela UNESCO, nos inícios da década de 1950.

Em 1946, já como etnógrafo consagrado, Alfred Métraux é convidado para participar do Departamento de Ciências Sociais da Organização das Nações Unidas para a Educação, a Ciência e a Cultura (UNESCO), primeiro como consultor, depois como membro permanente. Nessa instituição permanece até 1962, pouco antes de morrer. Naquele contexto de pós-guerra, pensava-se que o Brasil podia oferecer ao mundo um paradigma de relações raciais supostamente não conflitivo. Tratava-se, portanto, de lidar - desta vez através de um imenso projeto de pesquisa empírica - com os desafios decorrentes do discurso da "democracia racial" promovido pelas famosas formulações lusotropicalistas de Gilberto Freyre. Cabe aqui a pergunta: até que ponto a familiaridade de Métraux com a obra de Freyre constitui uma dimensão necessária para compreender o seu papel à frente do projeto sobre relações raciais no Brasil? Nestas páginas exploro, precisamente, as circunstâncias nas quais Métraux toma conhecimento da obra do pernambucano e, ao mesmo tempo - partindo, sempre, da sua intervenção na UNESCO -, indago sobre os limites e tensões em torno aos dilemas da antropologia aplicada. De fato, Métraux, como muitos de seus colegas na época, confiava no papel que as ciências sociais deviam assumir para lutar, em várias frentes, contra o racismo. De todas as formas, em algumas circunstâncias, chegou a evidenciar um certo ceticismo diante da suposta eficácia do papel intervencionista da chamada antropologia aplicada. Mas suas dúvidas e angústias como pesquisador - e seu mal-estar como funcionário ao serviço da UNESCO - não foram manifestadas publicamente, senão através de uma correspondência privada mantida com seu amigo e confidente Pierre Verger.

\section{ITINERÁRIOS DE ALFRED MÉTRAUX}

Apesar de ter nascido na Suíça (Lausana) em novembro de $1902,{ }^{2}$ Alfred Métraux passou toda sua infância em Mendoza, Argentina, onde seu pai 
trabalhou como cirurgião. Sua mãe, educada num contexto familiar judaico, era originária da cidade georgiana de Tbilisi. Segundo Rhoda Métraux - sua segunda esposa -, as precoces experiências naquela província argentina teriam moldado a curiosidade do futuro etnógrafo. ${ }^{3}$

No entanto, o meio intelectual europeu também estimulou sua sensibilidade etnográfica. Assim, em uma entrevista concedida em 1961, Métraux admitia que sua opção pela etnologia resultara da ebulição intelectual que sacudia a Europa dos anos 20, caracterizada por uma busca de descentramento e de ampliação da experiência através do "exótico" (Métraux 1964). Um sintoma deste ambiente - modernista - era a fascinação que alguns movimentos artísticos, como o surrealismo, manifestavam, por exemplo, em relação à chamada arte primitiva. Por esse caminho enveredaram, também, outros etnólogos próximos ao movimento surrealista - e amigos de Métraux -, como Michel Leiris e Georges Bataille. ${ }^{4}$ Mas, apesar de o próprio Métraux ter admitido a influência destas correntes no seu incipiente espírito antropológico, sua vocação não estava marcada por uma simples inquietação estética nem, muito menos, por uma revolta irracionalista contra a "razão burguesa" ou coisa parecida. Ao contrário, seus compromissos e seus esforços orientam-se, sempre, pelas coordenadas de uma rigorosa preocupação com a descrição e a comunicação dos fatos etnográficos.

Métraux recebeu educação secundária em Lausana. Entre 1922 e 1923 segue seus estudos na École Nationale des Chartes, em Paris, onde conhece Georges Bataille. Mais tarde ingressa na Sorbonne, onde obterá, em 1928, seu doutorado, com uma tese sobre a "civilização material" dos tupi-guarani. Nesse ínterim, obtém um diploma na École Nationale des Langues Orientales (1926) e uma especialidade em sociologia da religião na École Pratique des Hautes Études (1927). Dentre seus mestres da época, Marcel Mauss e, sobretudo, Paul Rivet, foram os mais influentes. A seguir, aperfeiçoa seus estudos etnográficos junto ao americanista sueco Erland Nordenskiöld, na Universidade de

[continuação] Dictionary of Anthropologists, a data de nascimento que figura, segundo o texto escrito por Rhoda Métraux (1991), é 1905; é possível que se trate de um lapso de edição. Aqui preferimos manter a de 1902, que é a que consta em várias das suas biografias e obituários (Dreyfus 1991; Friedman 1963; Le Bouler 1994; Wagley 1964).

3 A única referência bibliográfica que encontramos sobre este interesse inicial de Métraux em Mendoza é um artigo intitulado "Contribution à l'ethnographie et à l'archéologie de la province de Mendoza (Rep. Argentina)” (Métraux 1929).

4 Vale sublinhar a forte amizade que mantiveram Alfred Métraux e George Bataille, fundador da revista Documents, na qual colaboravam, igualmente, intelectuais ligados ao movimento surrealista e vários etnólogos. A trajetória de Michel Leiris é um caso paradigmático de passagem da militância surrealista para a etnografia profissional. Para mais detalhes sobre a questão, ver o famoso capítulo sobre "surrealismo etnográfico" de James Clifford (1988). Em relação à participação de Michel Leiris no movimento surrealista, ver a entrevista concedida a Sally Price e Jean Jamin (1988). Sobre a relação intelectual entre Métraux e Bataille, ver Métraux (1963a). 
Gotemburgo. A formação de etnólogo não o impedirá, no entanto, de abordar outros campos, como a linguística, a etno-história e a arqueologia. De qualquer maneira, Métraux preferia se autodefinir como "um homem de terreno", ou seja, um pesquisador cujo principal objetivo consistia em construir os dados em contato direto com os diversos ambientes socioculturais, e seus respectivos atores, através do trabalho de campo. Como veremos, esta "autodenominação" terá um significado marcante, sobretudo mais tarde, quando, temporariamente afastado da pesquisa de campo, deve assumir seu posto como funcionário das Nações Unidas.

Depois de finalizar seus estudos na Europa, Métraux retorna imediatamente para a Argentina. Ali, estar-lhe-ia destinada uma tarefa pioneira: a fundação e direção do Instituto de Etnologia da Universidade de Tucumán. Foi, precisamente, a instância de um convite formulado pelo próprio reitor da Universidade - Juan B. Terán -, amigo, na altura, de Paul Rivet, que essa "operação de retorno" foi viabilizada. Durante seis intensos anos (1928-1934), Métraux realiza trabalhos de campo entre vários grupos indígenas da região, escreve etnografias e dirige a revista de etnologia do mencionado instituto, que se converteria em um rico material de consulta para os antropólogos americanistas da época.

Durante seus anos na Argentina, Métraux, longe de se fechar nos muros da vida universitária, participa ativamente da vida intelectual e cultural do país. Um dos capítulos menos conhecidos desta fase é o da relação que estabelece com o grupo de intelectuais - dentre eles o escritor Jorge Luis Borges, na altura quase um desconhecido - próximo a Victoria Ocampo, fundadora da revista Sur. Métraux se tornará um ativo colaborador da revista, mas não deixará de criticar o espírito elitista do grupo. Um dos embates mais fortes com Victoria Ocampo (herdeira da grande aristocracia fazendeira da província de Buenos Aires) nasce quando Métraux sentencia que Sur estaria condenada a ser, simplesmente, uma "planta de estufa" em um país pleno de inclemências e que, portanto, só poderia sobreviver sob essa falsa proteção. Victoria Ocampo - cuja francofilia intelectual era indissimulável - teria ficado arrasada com a crítica do seu amigo. A reconciliação entre ambos viria tarde demais. Um ano antes de morrer, Métraux escreve um opúsculo intitulado "Victoria Ocampo e a etnologia": "É necessário lembrar", interrogava Métraux (1980 [1962]: 75), "que graças a Victoria Ocampo o grande público de fala espanhola conheceu a obra de Ruth Benedict, Patterns of Culture, que marca uma etapa importante na evolução da nossa disciplina e que a revista Sur ofereceu, sempre, sua hospitalidade às ciências humanas?" Poucos meses depois, Victoria Ocampo recebe, com surpresa, a notícia da morte de Métraux e decide escrever - sob a forma de uma conversa imaginária - uma afetuosa carta que, obviamente, seu amigo jamais leria (Ocampo 1967).

Em 1934, Métraux abandona Tucumán e retorna a Paris. Coincidentemente, na altura deste retorno, a antropologia argentina começa a ser hegemonizada, 
primeiro, por uma visão histórico-culturalista um tanto ultrapassada e, uma década mais tarde, por uma preocupação teórica derivada de certo tipo de fenomenologia que transitava na contracorrente do que, entre os anos 40 e 50, acontecera na moderna antropologia, tanto europeia (França, Inglaterra), como americana (Estados Unidos, México, Brasil). Por outro lado, as circunstâncias decorrentes de uma ditadura militar - a década de 1930 foi conhecida, na Argentina, como a "década infame" - começam a tornar irrespirável o ambiente acadêmico e político para o jovem etnógrafo.

Pouco tempo depois da sua chegada em Paris, Métraux se une a uma grande expedição franco-belga que empreende uma investigação na Ilha de Páscoa. Recorre várias ilhas da Polinésia e, por volta de 1938, organiza um grande volume com o resultado dos seus estudos. Entre 1936 e 1938 é contratado pelo Bishop Museum de Honolulu. Nesse ínterim, sua proximidade com os antropólogos norte-americanos (Robert Lowie, Alfred Kroeber, Margaret Mead, e o “jovem" Charles Wagley, dentre outros) se faz cada vez mais intensa. Em 1939 retorna à Argentina e Bolívia, onde realiza um novo trabalho de campo. Pouco tempo depois, no verão de 1941, inicia suas famosas investigações sobre o vudu no Haiti. Em breve, suas etnografias e trabalhos etno-históricos sobre os indígenas do Grande Chaco e os tupi-guarani do Brasil central se convertem em clássicos da disciplina, assim como seus trabalhos sobre a Ilha de Páscoa e o Haiti. ${ }^{5}$

Ao longo destes anos Métraux desenvolve, também, uma intensa atividade docente. Ensina nos Estados Unidos (Universidades de Califórnia e Yale), na Escola Nacional de Antropologia, México (1943), mais tarde na Faculdade Latino-Americana de Ciências Sociais, Chile (1959-60) e, nos últimos anos de sua vida, desempenha o cargo de professor de etnologia sul-americana na École Pratique des Hautes Études, em Paris. Nesses últimos anos cumprirá um papel central no envio de alguns dos seus melhores discípulos para desenvolverem trabalho de campo na América do Sul: Lucien Sebag e Pierre Clastres.

Como autoridade indiscutível em matéria de etnografia, Métraux é convidado, em 1941, a fazer parte do staff do Departamento de Etnologia Americana da Smithsonian Institution nos Estados Unidos. Durante toda a Segunda Guerra Mundial, desempenha um papel central naquela instituição, contribuindo com a elaboração do monumental Handbook of South American Indians (1946). Assim como outros intelectuais da época, para os quais se tornara difícil continuar trabalhando em uma Europa arrasada pela guerra, decide obter a cidadania norte-americana. Mas esta decisão circunstancial não debilita seus

5 Em ordem cronológica, as principais obras deste período são: L'Ile de Pâques (1941); The Native Tribes of Eastern Bolivia and Western Mato Grosso (1942); Ethnography of the Chaco: Handbook of South American Indians (1946). Alguns anos mais tarde é publicada sua pesquisa sobre o vudu em Haiti: Le Voudou Haitien (1958). 
laços com a Europa, cuja reconstrução requeria, segundo Métraux, uma firme intenção de unidade e compreensão intercultural. Em 1945 - com o auge, nos Estados Unidos, da chamada antropologia aplicada - chegou a integrar uma comissão de sociólogos e psicólogos "encarregados de estudar nas vésperas do armistício os efeitos psicológicos e sociais dos bombardeios sobre as cidades alemãs" (Métraux apud Monnier 2003: 16). ${ }^{6}$ Mas sua intervenção no campo da antropologia aplicada será intensa, sobretudo, no seio da UNESCO.

\section{A DOMESTICAÇÃO DO ETNÓGRAFO}

Por ocasião da Missão Cultural Francesa, Alfred Métraux é convidado, em 1946, a participar ativamente do secretariado das Nações Unidas. Seu espírito cosmopolita e o conhecimento em primeira mão de diversas realidades socioculturais o convertem em um candidato ideal para este empreendimento. Naquele momento, o drama do pós-guerra clamava a colaboração das ciências sociais para uma reconstrução global pautada na tolerância e na compreensão intercultural. As consequências do nazismo na Europa, a emergência do apartheid na África do Sul com o triunfo, em 1948, do Partido Nacional, bem como a segregação racial nos Estados Unidos e a persistência do colonialismo na África, prenunciam que a tarefa não seria fácil. De todas as formas, mesmo ciente das dificuldades, Métraux converte-se em um promotor da antropologia aplicada e, em 1950, quando assume o cargo de membro do Departamento de Ciências Sociais da UNESCO, começam a se concretizar numerosos projetos nas áreas de educação e desenvolvimento. ${ }^{7}$

Devemos lembrar que, tal como assinalaram Neiburg e Goldman (1998), a consagração da chamada antropologia aplicada nos Estados Unidos opera no contexto do surgimento dos estudos sobre o "caráter nacional". Com a entrada dos Estados Unidos na Segunda Guerra Mundial, um grupo de antropólogos (Margaret Mead, Gregory Bateson, Geoffrey Gorer, Ruth Benedict, entre outros) participa ativamente de projetos diretamente vinculados ao Departamento de Estado norte-americano. O conhecimento das diversas "culturas nacionais" supostamente ofereceria as mais eficazes ferramentas, tanto para conhecer o inimigo, quanto para manter o "moral" dos Estados Unidos durante a guerra. Depois da guerra, já no seio da UNESCO, as "nações" continuaram sendo objeto da antropologia aplicada, empenhada, desta vez, na reconstrução global e no reordenamento das relações internacionais.

6 Trata-se de uma informação fornecida pelo próprio Alfred Métraux numa carta, datada de 22 de outubro de 1953, enviada ao diretor do Instituto de Etnologia da Universidade Nacional de Tucumán.

7 No seu livro sobre o desenvolvimento da antropologia aplicada, George M. Foster (1969: 216-217) faz alusão ao importante papel de Alfred Métraux nesse campo. Uma data-chave no processo de legitimação da chamada antropologia aplicada é 1941. Naquele ano é realizada a primeira reunião, na Universidade de Harvard, da Sociedade para a Antropologia Aplicada. 
Entre as iniciativas mais ambiciosas deste período da UNESCO destacam-se o projeto vinculado à criação do Instituto da Hileia Amazônica e a missão para desenvolver uma investigação-piloto sobre educação no Haiti entre 1948 e 1950 (Métraux 1951a). No entanto, como veremos, o empreendimento de maior alcance foi o projeto sobre "relações raciais" no Brasil. Este consistiria em uma ampla pesquisa empírica, cujo universo de análise abrangeria várias regiões do país. ${ }^{8} \mathrm{O}$ objetivo, neste caso, consistia em indagar, por um lado, se o Brasil poderia oferecer um modelo não conflituoso de relações raciais ao mundo e, por outro lado, avaliar os alcances e as contradições da chamada "democracia racial" brasileira (Maio 1997).

Métraux ingressa na UNESCO em 1946, ou seja, apenas um ano após a criação da instituição. Seu primeiro diretor foi o biólogo inglês Julian Huxley. A ideia de que o conhecimento, neste caso proporcionado pelas ciências sociais, podia contribuir para a melhor aplicação das políticas de desenvolvimento fazia parte dos princípios fundamentais da instituição. No entanto, apesar das declarações públicas de intenção e da explicitação de uma "boa consciência", Métraux nunca se sentirá completamente cômodo no seio da UNESCO. Em uma carta ao seu amigo Pierre Verger, expressa um sentimento de incerteza quanto ao seu futuro como "homem de terreno":

“... surpreenderá a você o fato de saber que me transformei em um burocrata e em um funcionário... Finalmente fui empregado pelas Nações Unidas na divisão 'Estudos e Pesquisas', que se ocupa de projetos científicos, e é assim que me tornei funcionário. É verdade que este destino tem compensações: um salário agradável e uma companhia das melhores como a da Smithsonian. Mas, por agora, devo dizer adeus aos igarapés, aos negros e aos índios, o que me deixa um gosto amargo na boca e um peso em minha consciência. Para diminuir esse peso, estou projetando em dezembro uma escapada de alguns dias para as Guianas francesas, a fim de ver os maroni, e de respirar o ar dos trópicos. Sem esta perspectiva, o horizonte que teria diante de meus olhos seria insuportável. Serei portanto funcionário até que chegue um dia no qual me encontre melhor e possa voltar a ser fiel a mim mesmo" (Métraux e Verger 1994: 71).

Três anos depois, em 1949, quando o projeto sobre "relações raciais" no Brasil ainda não estava concretizado, Métraux se encontrava no Haiti, realizando um levantamento etnográfico como parte do projeto sobre educação

8 Esta grande pesquisa incluiu, também, a compilação e edição de um conjunto de trabalhos que abordavam os aspectos teóricos derivados da tensa relação entre "raça" e "cultura". Entre os antropólogos recrutados para esta tarefa encontravam-se Claude Lévi-Strauss, bem como Michel Leiris, Otto Klineberg e Juan Comas. 
que a UNESCO possuía no vale de Marbial (Laurière 2005). Nessa altura, seu amigo Pierre Verger torna-se uma espécie de confessor. Em um dos seus intercâmbios epistolares, Métraux volta a revelar sua angústia diante de um suposto projeto de "antropologia aplicada" que parecia naufragar entre os labirintos burocráticos das Nações Unidas e das grandiloquentes empresas humanitárias. Desta vez, com um tom de frustração, Métraux se pronuncia nestes termos:

"O projeto de Marbial vegeta e toma um caráter cada vez mais sórdido. Os camponeses morrem de fome ainda mais rápido que no ano passado. Quanto à UNESCO, que nos enviou um alto funcionário, ele se comporta como certos tipos fracassados que sempre desprezam a tarefa presente em favor de planos grandiosos ao lado dos quais a realidade na qual os vemos entreter-se não mereceria figurar. Tudo toma, pois, o aspecto de uma farsa e de uma mistificação que começa seriamente a enfadar de tal maneira que os meses passam e não há perspectivas do meu regresso à França. Este ano é, sem dúvida, o último que passo na UNESCO, pois ignoro se possuo humor para viver assim, na irrealidade de um universo onde as relações e as conferências são a única substância. Infelizmente, há que viver, e não tenho outra alternativa que a de retomar ao meu posto nas Nações Unidas onde levarei uma vida subterrânea e tediosa..." (Métraux e Verger 1994: 105).

O projeto sobre educação e desenvolvimento no Haiti fora aprovado na Conferência Geral da UNESCO, no México, acontecida em 1947. Desta pesquisa "aplicada", financiada pelo Viking Fund, participaram especialistas de diversas disciplinas. Métraux, com a cooperação de estudantes haitianos, encarregou-se de dirigir o trabalho etnográfico cujos objetivos foram resumidos, mais tarde, em um artigo publicado na revista América Indígena (Métraux 1949).

Apesar do mal-estar expresso nas cartas dirigidas ao seu amigo Pierre Verger, seria um tanto arriscado postular que a colaboração de Métraux com a UNESCO obedecia a uma simples inércia, justificada por um bom salário e uma vida sem sobressaltos. Neste sentido, o projeto sobre relações raciais no Brasil é um bom exemplo de que sua participação na mencionada instituição veiculava uma preocupação acadêmica legítima, fundada, em última instância, em profundas convicções antirracistas. Talvez um dos sintomas dessas inquietações resida no interesse intelectual que Métraux expressou, desde os primórdios, em relação à obra de Gilberto Freyre - um interesse, portanto, que surge muito antes de o projeto sobre as relações raciais no Brasil estar nos planos de seus formuladores.

\section{ALFRED MÉTRAUX LUSOTROPICALISTA?}

Em setembro de 1940, sendo professor de antropologia na Universidade de Yale, Alfred Métraux envia uma carta a Gilberto Freyre, cujo livro Casa-Grande 
\& Senzala fora publicado em 1933. Nessa ocasião, Métraux já era um etnógrafo reconhecido, tanto no Brasil como alhures. A carta manifesta uma inconfundível admiração por aquela obra:

"Acabo de ler essa obra prima de sociologia americana que é Casa Grande \& Senzala. Permittame que me congratule com o autor por um livro como esse, único na matéria e certamente uma das maiores contribuições da América Latina às sciencias sociaes. Este anno estou na Universidade do Yale, realizando conferencias sobre a ethnologia sul-americana, particularmente brasileira, e farei largo uso de seu livro. Peço-lhe informar-me si algum editor americano já cogita de publicá-lo em inglês, pois estimaria eu próprio encarregar-me disso, certo de que o livro será aqui extremadamente bem recebido". ${ }^{9}$

Na verdade, a tradução ao inglês de Casa-Grande \& Senzala (The Masters and the Slaves) só sairia à luz em 1946 sob a tradução de Samuel Putnam, que, pouco tempo depois, se consagraria como o grande tradutor americano de Miguel de Cervantes. Cabe recordar que, no mesmo ano em que recebera aquela carta de Métraux, Gilberto Freyre acabara de elaborar, a convite do Instituto Luso-Brasileiro de Alta Cultura, uma série de conferências para serem lidas na Europa (que, mais tarde, seriam republicadas sob o título O Mundo Que o Português Criou). Na altura, a doutrina lusotropicalista, veiculadora de uma apologia do colonialismo português e da suposta "plasticidade" da forma portuguesa de estar no mundo, ainda não estava totalmente consumada. No entanto, o elogio à "mestiçagem" racial e cultural na obra de Freyre começava a ser uma ferramenta para pontificar acerca da suposta singularidade da colonização portuguesa. ${ }^{10}$ Em todos os lugares onde dominou este tipo de colonização, afirmava Freyre, “... o preconceito de raça se apresenta insignificante, e a mestiçagem, uma força psicológica, social e, pode-se mesmo dizer, eticamente ativa e criadora..." (Freyre 1940: 45-46).

Em Casa-Grande \& Senzala, aquele retrato do colonizador aparece sob a forma de um microuniverso de sociabilidades e sensibilidades (o da casa grande

9 Transcrição literal de um excerto de "Um livro Brasileiro julgado por um grande scientista francez: uma carta do professor Métraux ao Sr. Gilberto Freyre”, Diario de Pernambuco, 15 de setembro de 1940 (secção de Hemeroteca, Biblioteca Nacional do Rio de Janeiro).

10 A bibliografia sobre o assunto é imensa. Alguns autores, como Roger Bastide, preferiram tomar o lusotropicalismo como um tipo específico de "teoria sobre a aculturação". Segundo Bastide, “... o que Gilberto Freyre denominou 'lusotropicalismo' é uma ideologia política tanto quanto uma 'ciência' propriamente dita. Mas é contudo, ciência, e desse ponto vamos analisá-la, deixando de lado as implicações que tenha podido ter a favor do manutenção do colonialismo português. Por outro lado, a recepção que este lusotropicalismo teve em certas universidades europeias, especialmente as inglesas, nas quais se criaram institutos para estudar a ação dos trópicos sobre os brancos e suas culturas étnicas, destaca cabalmente tal aspecto científico. Isso prova que o lusotropicalismo constitui algo mais que uma simples apologia de Portugal, mesmo que essa apologia não deixe de ser um dos elementos que o integram” (Bastide 1972: 87). 
e da senzala) num onipresente contexto escravocrata. Eis o aparente paradoxo: no âmbito da família patriarcal, o retrato dessas relações de proximidade física entre negros e brancos, entre escravos e senhores, é, também, acompanhado por imagens de violência e sadismo - ainda o "jovem" Gilberto Freyre de Casa-Grande \& Senzala estava longe de se transformar no "maduro" lusotropicalista. Por isso, tal como adverte Ricardo Benzaquen de Araújo, a imagem bucólica de convivência racial em Casa-Grande \& Senzala é tão forte quanto as imagens de violência cotidiana: “... podemos perceber que, apesar da mestiçagem, da tolerância e da flexibilidade, o inferno parecia conviver muito bem com o paraíso em nossa experiência colonial" (Araújo 1994: 48).

$\mathrm{O}$ interesse de Métraux pelo livro de Freyre não passará despercebido em Recife, cidade natal do "sociólogo" brasileiro. Naqueles dias - fevereiro de 1941 -, o Diário de Pernambuco entrevistaria o próprio Gilberto Freyre. É nessa ocasião que Freyre informa que Casa-Grande \& Senzala, além de ter despertado o interesse de Métraux, chegara a ser elogiado pelo filósofo Ortega y Gasset, que teria solicitado autorização para publicá-lo em espanhol. ${ }^{11}$

Consideramos que este primeiro contato que Métraux estabelece com a obra de Freyre não deve ser entendido como um acontecimento isolado em relação ao seu posterior papel como organizador do projeto sobre "relações raciais" no Brasil, dentro do Departamento de Ciências Sociais da UNESCO.

Cabe lembrar que, no momento do início do projeto sobre "relações raciais" no Brasil, encontrava-se na direção da UNESCO o intelectual mexicano Jaime Torres Bodet. ${ }^{12}$ Foi ele, precisamente, quem contribuiu para a eleição de Arthur Ramos como diretor do Departamento de Ciências Sociais. A partir do trabalho precursor de Verena Stolcke - aprofundado por Marcos Chor Maio -, sabemos que o intermediador da nomeação de Arthur Ramos para esse cargo foi Paulo E. de Berredo Carneiro, “... intelectual positivista de S. Paulo e delegado permanente do Brasil no conselho Diretor da UNESCO” (Stolcke 1998: $211)$. Arthur Ramos, mais próximo dos "modernistas" de São Paulo - e mais afastado do centro de gravitação em torno a Gilberto Freyre -, foi considerado o candidato adequado para assumir aquele cargo. Contudo, poucas semanas após a sua nomeação, morre em Paris sem sequer começar os trabalhos à frente da instituição. ${ }^{13}$

11 A primeira tradução ao espanhol de Casa-Grande \& Senzala aparecerá em Buenos Aires, em 1942, numa coleção dedicada a autores brasileiros. A tradução ficará sob a responsabilidade de Benjamín de Garay, que já tinha traduzido outros "clássicos" da literatura brasileira.

12 Jaime Torres Bodet nasceu no México, em 1902. Foi poeta, educador e diplomático. Ocupou o cargo de professor de literatura francesa na Escola de Altos Estudos de México. Depois, atuou como embaixador na Espanha, França e Bélgica. Em 1943, representou o México na Conferência de Londres, quando foi criada a UNESCO. Ver, para mais detalhe, Marcos Chor Maio (1998).

13 Para aprofundar sobre a trajetória de Arthur Ramos, consultar, dentre outros, os trabalhos de Luiz Fernando Dias Duarte, Marcos Chor Maio, Mariza Corrêa, Verena Stolcke e Olívia Maria [continua] 
A iniciativa de levar adiante o projeto sobre relações raciais no Brasil começou a ser discutida em uma reunião realizada por um grupo de intelectuais reunidos na casa da UNESCO em Paris, no final de 1949, ainda com a presença de Arthur Ramos. Entre os participantes encontravam-se, também, Ashley Montagu e Franklin Frazier, dos Estados Unidos, Claude Lévi-Strauss, da França, Juan Comas, do México, e Costa Pinto, do Brasil. Após o falecimento de Arthur Ramos, Alfred Métraux assume a coordenação de uma divisão, dentro do Departamento de Ciências Sociais, dedicada à "questão racial". Nessa secção contará com a colaboração do antropólogo brasileiro Ruy Coelho (1920-1990). ${ }^{14}$ Assim, em 1. ${ }^{\circ}$ de abril de 1950, Métraux deixa Nova Iorque e se instala na sede da UNESCO em Paris.

Finalmente, a Quinta Conferência Geral da UNESCO, que ocorre em junho de 1950 em Florença, aprova a realização da pesquisa sobre "relações raciais". Um ano mais tarde, Alfred Métraux, já como diretor do projeto, publica no Correio da UNESCO um artigo com o sugestivo título "Brazil, land of harmony for all races?" (Brasil, terra de harmonia para todas as raças?). Nesse trabalho, Métraux faz um retrato - tantas vezes repetido por outros intelectuais - de um Brasil cuja configuração "racial" é irredutivelmente distinta daquela dos países de colonização anglo-saxã. Nesse caso, suas palavras veiculam a ideia de que a colonização portuguesa teria instaurado um tipo de padrão de relações raciais singular e, supostamente, não segregacionista:

"Enquanto que nos Estados Unidos e na África do Sul, as pessoas mulatas são classificadas como negras, ainda que tenham uma mínima quantidade de sangue negro, no Brasil é a posição social da pessoa a que conta muito mais do que a cor da pele. Neste aspecto, os brasileiros são autênticos herdeiros dos portugueses que nunca deram demasiada importância à raça e que se casaram livremente com todos os povos nativos que conquistaram e colonizaram" (Métraux 195 lb: 3)

A cor da pele no Brasil, diz Métraux, não constitui uma barreira. Neste aspecto, o Brasil se distinguiria dos Estados Unidos. Como sabemos, esse é, precisamente, um dos argumentos fulcrais da doutrina lusotropicalista de Gilberto Freyre. Ou seja, a narrativa apologética acerca do êxito da colonização portuguesa se apoia na suposta existência de um tipo de plasticidade e tolerância que estimulou a mistura e a fusão racial e cultural entre a metrópole e os "trópicos". Os detentores deste argumento contrastam, por sua vez,

[continuação] Gomes da Cunha apresentados no Seminário "Diários de Campo: Arthur Ramos, Antropologia e Psicanálise no Brasil” e publicados nos Anais da Biblioteca Nacional (AAVV 1999).

14 Rui Coelho foi aluno de Roger Bastide na Faculdade de Filosofia, Ciências e Letras da Universidade de São Paulo. Estudou com Melville Herskovits na Universidade de Northwestern e realizou sua tese de mestrado sobre aculturação entre os caraíbas negros de Honduras. Ver Maio (1998). 
as consequências "benignas" da colonização portuguesa com o padrão que o modelo de relações raciais teria criado nos Estados Unidos e na África do Sul.

No entanto, cabe adiantar, Métraux não cairá no extremo de promover uma visão idílica, a ponto de descartar as possibilidades de discriminação e preconceito racial no Brasil. Neste caso, para além da existência de uma estigmatização em relação à cor ou da persistência de um "preconceito de marca", segundo a famosa noção cunhada por Oracy Nogueira (1955, 1998), o que essas atitudes ocultam é, em última instância, um tipo bem concreto de preconceito social ou de classe. Assim, segundo Métraux - e no encalço das análises aprimoradas, mais tarde, por Florestan Fernandes - o Brasil assistia, naquela época, ao desenvolvimento de um inconfundível racismo entre as classes trabalhadoras das cidades como São Paulo e Rio de Janeiro. As origens deste racismo seriam econômicas, e se evidenciariam através do medo dos trabalhadores brancos diante da concorrência com um proletariado não especializado e desertor das áreas rurais que procurava integrar-se a uma indústria em expansão. Outra forma de expor este mesmo argumento, tal como fizeram outros investigadores, expressa-se na frase, um tanto banal, de que no Brasil o dinheiro "branqueia". Neste caso, o preconceito de classe seria mais forte que o preconceito racial. ${ }^{15}$

Alfred Métraux não podia, nessa etapa embrionária do projeto UNESCO no Brasil, extrair conclusões prematuras. Sua posição limita-se a expor os dilemas, as tensões e as interrogações que a própria investigação deveria esclarecer. Por isso, neste contexto, Métraux não abandona sua aguçada sensibilidade etnográfica. A preocupação com os dados deve prevalecer, portanto, diante das especulações históricas e das reconstruções apressadas:

"Os primeiros levantamentos, sobretudo os trabalhos históricos de Gilberto Freyre e as pesquisas sociológicas de Donald Pierson na Bahia, tinham já confirmado as opiniões positivas, amplamente formadas, acerca da situação racial no Brasil; porém, ainda havia dúvidas sobre o assunto. Alguns incidentes e algumas raivosas reclamações feitas por organizações negras sugeriam que as relações raciais não eram tão harmoniosas quanto muitos brasileiros e estrangeiros queriam acreditar... Mas mesmo que não tivessem soado quaisquer vozes discordantes, a harmonia existente precisaria ainda de ser esclarecida e explicada através de exemplos concretos" (Métraux 1952: 6).

15 No Brasil, diz Carl Degler, um branco pode ser "um branco muito rico, um branco medianamente rico, um branco pobre, um mulato muito rico, um mulato medianamente rico, um negro muito rico" (1976: 116). No entanto, Degler previa, na altura, uma crescente polarização, ao estilo norte-americano, das relações raciais no Brasil. 
Métraux conhecera, sem dúvidas, os processos tortuosos da pesquisa empírica. $\mathrm{Na}$ qualidade de etnógrafo e estudioso dos cultos afro-americanos, postulava, por exemplo, a ideia de que o Brasil devia reconhecer a contribuição das "civilizações negras" decorrente da importação de milhões de escravos da África. A colonização do Brasil, diz, "foi uma aventura compartilhada por brancos e negros, os quais, mesmo contra suas inclinações, trabalharam juntos para instaurar um novo meio social. A singularidade da vida brasileira deriva, em um certo ponto, destas tradições africanas que moldaram o caráter nacional" (1952: 6).

Esta preocupação de estabelecer e definir a singularidade de um caráter nacional perpassa, como sabemos, todo o trabalho de Freyre. Ora, essa constatação não necessariamente torna Alfred Métraux um freyriano convicto. $\mathrm{Na}$ verdade, a preocupação pelo estudo, em diversos contextos, do chamado caráter nacional integrava, há vários anos, a agenda de pesquisas da antropologia norte-americana. Até certo ponto, os estudos sobre o caráter nacional serviram de modelo aos cientistas sociais das Nações Unidas, convencidos de que o conhecimento das supostas idiossincrasias das nações era uma condição para a compreensão intercultural e para a melhor convivência entre elas.

Do projeto da UNESCO sobre "relações raciais" participaram numerosos antropólogos e sociólogos. Cada um deles ficaria responsável por uma região específica. Cabe sublinhar que, naquelas circunstâncias, os estudos sobre "comunidades" estavam na ordem do dia. Foi, precisamente, no quadro dessa inspiração metodológica - perpassado pelo famoso paradigma do continuum rural-urbano - que muitas dessas pesquisas se desenvolveram. Tal como Josildeth Gomes Consorte afirmou numa entrevista recente (Figueiredo, Oliveira e Damasceno 2009), nas vésperas do "grande projeto" da UNESCO concebido por Métraux, já estavam se desenvolvendo outros dois projetos, cujos pesquisadores acabariam se integrando àquele projeto maior: o projeto no Vale do São Francisco, desenvolvido por um grupo de sociólogos vinculados à Escola Livre de Sociologia e Política, em São Paulo, e o projeto "Columbia University/Estado da Bahia”, concebido graças aos auspícios de Anísio Teixeira e do qual participaram Thales de Azevedo (Bahia) e Charles Wagley (Columbia) junto a três discípulos, dentre os quais Marvin Harris:

"Quando o Métraux chegou com o projeto da UNESCO em janeiro de 1951 na Bahia, já fazia seis meses que nós estávamos em campo. Ele chega com aquela proposta maravilhosa de estudo das relações raciais. Claro, todo mundo ficou encantado e cada um dos três rapazes [Marvin Harris, Harry Hutchinson e Benjamin Zimmerman] ficou encarregado de dedicar uma atenção especial às relações raciais" (Figueiredo, Oliveira e Damasceno 2009: 205-206). 
Portanto, a partir da Bahia, Charles Wagley, ${ }^{16}$ Marvin Harris (na época discípulo de Wagley) e Thales de Azevedo foram integrados no projeto UNESCO. Entretanto, no estado de São Paulo, destacaram-se, entre outros, os trabalhos de Roger Bastide, Florestan Fernandes e Oracy Nogueira. No caso do Rio de Janeiro, as contribuições de Luiz Aguiar de Costa Pinto foram, também, fundamentais. Mais tarde, René Ribeiro, desde Recife, incorpora-se ao projeto, a partir de um convênio no qual estava envolvida a Fundação Joaquim Nabuco - e, portanto, o próprio Gilberto Freyre (Maio 1999a). A necessidade de considerar um escopo amplo para o desenvolvimento do projeto foi formulada, desde os primórdios, pelo próprio Métraux, que, nas vésperas do início da pesquisa, afirmava de forma enfática:

"A região da Bahia, em si mesma se presta admiravelmente para o estudo da questão racial no Brasil, devido à sua grande percentagem de negros. Porém, a pesquisa deveria focar, também, outras regiões do Brasil que, do nosso ponto de vista, mostram consideráveis diferenças. As relações entre negros e índios também não deveriam ser desconsideradas, já que no passado tiveram uma importante influência no desenvolvimento da cultura brasileira... Finalmente, a suposta assimilação dos negros nas grandes cidades do sul do Brasil, precisa, também, ser verificada cientificamente" (Métraux 1950: 389).

Em 1951, Métraux realiza uma viagem ao Brasil para se reunir com alguns colaboradores locais do projeto. Em seu diário e caderno de viagens encontram-se breves anotações sobre algumas dessas conversas de trabalho. Depois do encontro com Thales de Azevedo, em Salvador, Métraux deixa o seguinte registro: "Os âmbitos mais 'racistas' no Brasil são as forças armadas, a marinha e as ordens religiosas, sobretudo as ordens femininas"; e acrescenta, quase que em forma de telegrama: "Discriminação racial mais forte entre os comerciantes do que entre as profissões liberais" (Métraux 1978: 325). No registro referente a essa mesma reunião, aparecem, também, algumas frases soltas em português. Dentre elas, vale evocar a seguinte: "O preconceito não é ostensivo, mas na intimidade se sente" (1978: 325). Possivelmente tratava-se de uma frase textual pronunciada pelo próprio Thales de Azevedo e que Métraux incorporara ao seu caderno de anotações. Poucos dias depois se desloca a São Paulo, onde teve sucessivas reuniões e conversas - uma delas na Escola Livre de Sociologia e Política - com Oracy Nogueira, Roger Bastide, Florestan Fernandes e Costa

16 Charles Wagley (1964: 605) conta que conheceu Alfred Métraux em 1939, na Universidade de Yale. Em sua primeira viagem à América do Sul, Wagley, convidado por Métraux, pensava iniciar um trabalho de campo na região do Chaco argentino. Finalmente opta pelos tapirapé, um grupo tupi do Brasil central. Métraux exerceu um papel central ao inserir Wagley nos meios acadêmicos brasileiros, mais especificamente entre seus colegas antropólogos do Museu Nacional de Rio de Janeiro. Ver, também, Corrêa (1988). 
Pinto, dentre outros. Em seu diário, Métraux registra os resultados do encontro com Florestan Fernandes, que acabava de finalizar seu doutorado. O relato é particularmente ilustrativo, já que apresentava algumas das preocupações que Florestan desenvolveria, mais tarde, em vários de seus trabalhos:

"Florestan Fernandes pensa que o problema racial é, sobretudo, uma questão de urbanização. Quando os emigrantes brancos chegaram, participaram do desprezo para com o negro, trabalhador manual. Depois, os negros avançaram e se fizeram aceitar pela sociedade brasileira. O negro que recentemente chega do campo, quer seguir esse exemplo. Encontra resistência e sofre. O que ainda permanece incerto é a maneira que ele encontrará para sair dessa situação. Será que optará, como os brancos, pela saída individualista, ou bem se organizará como um grupo diferente e formará uma 'frente negra'?" (Métraux 1978: 330).

Nos últimos anos - e a partir do trabalho pioneiro de Marcos Chor Maio -, a bibliografia e o interesse sobre as pesquisas desenvolvidas pelo projeto UNESCO têm aumentado consideravelmente. Em 2004, o Centro de Estudos Afro-Orientais (CEAO) da Bahia organizou um importante evento para comemorar os 50 anos do projeto. Infelizmente, naquela comemoração, Métraux não ocupou um lugar de destaque. ${ }^{17}$

Talvez a atualidade do projeto UNESCO não deva ser medida em relação ao maior ou menor grau de obsolescência ou atualidade dos seus resultados nas regiões do Brasil onde se aplicou. Certamente, se novas pesquisas fossem realizadas nos mesmos locais, os dados levantados, passados já 60 anos, evidenciariam novas dinâmicas. É possível que uma das heranças mais valiosas do projeto - para além das inegáveis, mesmo que datadas, contribuições empíricas - resida no fato de que ele ajuda a pensar os processos de produção do conhecimento sociológico e antropológico num contexto político regional e internacional específico. Ao mesmo tempo, o legado daquele gigantesco programa de pesquisa serve para pensar os limites, as contradições e as ambiguidades em torno de uma antropologia de "intervenção".

\section{FATOS, REPRESENTAÇÕES E OUTRAS DISPUTAS}

O itinerário empreendido por Alfred Métraux não transita por caminhos politicamente neutros e despojados de disputas e perpétuas buscas de

17 Os trabalhos apresentados naquele evento ("O Projeto UNESCO no Brasil: uma volta crítica ao campo 50 anos depois") podem ser consultados em <http://www.ceao.ufba.br/unesco>. Além da já referida tese de Marcos Chor Maio (1997) e seus vários artigos (1998, 1999a, 1999b), para uma avaliação destas pesquisas, ver também Guimarães (1996), Arruda (1996), Macagno (1999), dentre outros. 
legitimidade. Em todo caso, o que sua trajetória no seio da UNESCO evidencia é a tensão entre um projeto intelectual emancipador, mais ou menos autônomo, e um contexto político derivado do pós-guerra, agravado, desta vez, pelas ansiedades crescentes da chamada Guerra Fria. Métraux, neste sentido, não demorará em manifestar sua preocupação e mal-estar quando as perseguições do macarthismo, nos Estados Unidos, começaram a atingir os seus colegas. $\mathrm{Na}$ altura, a própria Alva Myrdal - chefe da secção de ciências sociais da UNESCO e esposa do famoso sociólogo sueco Gunnar Myrdal ${ }^{18}$ - chegou a ser alvo de interpelações. Em uma carta enviada de Paris, datada de maio de 1953, antes de empreender uma nova viagem à América do Sul, Métraux escrevia a Pierre Verger nestes termos:

"Minha viagem aos Estados Unidos foi mais que enganosa, e deixei com um sentimento de alívio um país onde domina a loucura e onde o ar se tornou irrespirável para mim. O que é a caça às bruxas na África em comparação com a perseguição de que são objeto as pessoas, as mais simpáticas, nos Estados Unidos em nome de um conformismo político e moral, cuja simples descrição poderia fazer-nos vomitar? Hoje foi nossa diretora Mme Myrdal quem teve dificuldades, e sinto que em alguns meses minhas extravagâncias antirracistas me provocarão desgostos; mas o importante é permanecer em Paris, e daqui me preparo para as baixarias" (Métraux e Verger 1994: 180).

As perseguições às quais se refere Métraux alcançaram um grau de paroxismo em 1953, através do Senate Committee on Government Operations, cujo presidente era o senador republicano Joseph McCarthy. Um ano antes, o Partido Republicano havia triunfado nas eleições. A ascensão do macarthismo veiculou, entre outras coisas, a ideia paranoica de que o fracasso da política exterior norte-americana obedecia a uma espécie de conspiração interna da qual participavam, supostamente, intelectuais, artistas e escritores. Hoje - após a abertura dos arquivos correspondentes e graças à publicação do perturbador livro de David H. Price (2004) - sabemos que, entre o final da década de 1940 e ao longo de toda a década de 1950, dezenas de antropólogos que, nos Estados Unidos, trabalhavam ao serviço de organizações como a UNESCO ou do próprio Departamento de Estado, sofreram interpelações e perseguições do FBI. Entre eles encontravam-se o próprio Alfred Métraux, além de Marvin Harris, Charles Wagley, Ruth Landes e Robert Redfield (Price 2004: 170-171).

18 Gunnar Myrdal escreveu o famoso livro - publicado em dois grandes volumes - intitulado An American Dilemma: The Negro Problem and Modern Democracy, sobre relações raciais nos Estados Unidos. Publicado pela primeira vez em 1944, o livro de Myrdal exercerá uma influência decisiva na década de 1950. Assim, a chave do "dilema americano" consistia na contradição existente entre o "credo americano" da democracia, da igualdade, etc. e a realidade social de discriminação e segregação de que eram objeto os negros nos Estados Unidos. 
Certa vez perguntaram a Michel Leiris por quê, em uma homenagem póstuma, descrevera Métraux como um poeta. Nessa ocasião, sua resposta foi que tal descrição pretendia, simplesmente, significar que Métraux vivera de forma poética, ou seja, sob uma completa inadaptação em relação à "vida contemporânea" (Price e Jamin 1988: 168). Mas, a julgar pelas palavras de Leiris proferidas na mencionada homenagem, também era sua intenção, através desse retrato, chamar a atenção para a sensibilidade etnográfica de Métraux e sua preocupação em transmitir os fatos na sua "realidade singular" (cf. Leiris 1964: 15, em epígrafe neste artigo). Para além da evocação subjetiva veiculada por quem fora seu grande amigo, essa descrição evidencia o fato de que Métraux, possivelmente, lidava com uma espécie de "incômodo cultural": ou seja, um perpétuo estranhamento em relação ao mundo que o circundava. ${ }^{19}$ Como promotor da antropologia aplicada no seio da UNESCO, teve que conciliar os extremos da famosa distinção weberiana e transitar, por assim dizer, entre as exigências de uma "ética da responsabilidade" e, ao mesmo tempo, as de uma "ética dos fins últimos". O primeiro polo o condicionava a uma agenda de pesquisa internacional, cujos projetos de engenharia social demandavam imensos esforços organizativos e responsabilidades institucionais. $\mathrm{O}$ segundo extremo situava-o numa posição de crítica às aparentes certezas de um sistema de valores com pretensões de universalidade e com o qual ele - como "homem de terreno" - não compactuava: eis o momento no qual o trabalho etnográfico vem a descortinar as arbitrariedades desse universalismo limitado que, em última instância, não conseguia neutralizar as ameaças de uma modernidade perversa. Talvez por isso, como recordou Pierre Clastres - um dos seus grandes discípulos - Métraux gostava de se autodefinir como um "nostálgico do neolítico" (Clastres 1992: 33). Assim, contra aquele localismo trasvestido de um falso universalismo, a etnografia vinha, por assim dizer, interpelar e questionar as certezas de um "ocidentalismo" vulgar. O mapeamento da experiência humana, num registro alargado, realizado por Métraux nos mais diversos contextos etnográficos, abria, assim, um caminho para o questionamento de uma "razão instrumental" que - aos olhos do etnógrafo - parecia não fornecer saídas humanamente convincentes. Por isso, é compreensível, uma vez mais, sua simpatia inicial pelo movimento surrealista e, depois, sua definitiva opção pela

19 Um dos aspectos mais inquietantes da biografia de Métraux é o fato de que, precisamente, seu último trabalho publicado (uma reflexão sobre a velhice) situa-se em torno de um conjunto de coincidências "voluntárias" sobre o desenlace da sua própria vida. "Vivemos, sem dúvida alguma", dizia Métraux, "mais tempo que os 'selvagens', mas é um privilégio pelo qual temos pago caro" (Métraux 1963b: 23). Este artigo, publicado no Correio da UNESCO, tinha como título "Acaba-se a vida aos 60 anos...?" Essa era, precisamente, a idade de Métraux no momento em que decide pôr fim à sua vida. O referido artigo foi publicado no mesmo mês e ano (abril de 1963) do seu suicídio, no Vale de Chevreuse, na França. 
etnografia profissional. ${ }^{20}$ Neste caso, é possível aplicar a Métraux a sentença pronunciada pelo seu amigo Claude Lévi-Strauss, durante uma conversa que os dois mantiveram - acerca do "estado atual da etnografia" - em Nova Iorque. Naquela ocasião, Lévi-Strauss - já a caminho de se tornar um estruturalista afirmara que, nos Estados Unidos, a antropologia era uma "doença social que afetava as pessoas incapazes de suportar sua própria civilização" (Métraux 1978: 171). Conforme consta no seu diário pessoal, depois daquela conversa, Métraux foi envolvido por um sentimento de depressão ("Ele [Lévi-Strauss] deseja um retorno à filosofia, a uma concepção de conjunto. A antropologia seria, nos Estados Unidos, uma doença social que acomete as pessoas incapazes de suportar sua própria civilização. Fico preso numa imensa depressão. Uma péssima noite..."). Teria Métraux se sentido incluído no fatal "diagnóstico" de Lévi-Strauss?

Curiosamente, o Métraux etnólogo (o da "etnologia indígena") e o Métraux sociólogo (o das "relações raciais") raramente têm sido considerados na sua continuidade e na sua totalidade. Será que há, de fato, uma ruptura entre um e outro? Por algum motivo, os relatos acerca da sua trajetória acabaram por consagrar - literalmente, tornar "sagrada" - aquela separação dicotômica, ofuscando, assim, as próprias contradições e paradoxos de uma figura multifacetada e complexa. Efetivamente, Métraux, como "homem total" - para evocar aqui uma expressão maussiana - não restringiu suas indagações intelectuais às fronteiras de uma "pátria" disciplinar ou coisa parecida. Talvez, sua "nostalgia do neolítico", mesmo funcionando como um dispositivo de crítica cultural, possa, devido a sua ineficácia política, continuar nos incomodando (a "doença" antropológica à qual se referia Lévi-Strauss). Em troca, seu irremediável cosmopolitismo intelectual constitui, ainda, uma lição vigente.

Em julho de 1951 é aprovada, no Brasil, a proposta de lei elaborada por Afonso Arinos de Melo Franco (1905-1990) penalizando a discriminação racial (Lei 1390/1951). Justamente, poucos meses depois, era publicado, no Correio da UNESCO, um artigo de Alfred Métraux, no qual relatava, em tom elogioso, a importância da medida. No Brasil, dizia, "leis 'raciais' têm sido aprovadas para combater o preconceito racial mas não para lhe outorgar uma existência oficial" (Métraux 1952: 6). Nesse mesmo número da revista, na página seguinte ao artigo de Métraux, aparece uma nota de Gilberto Freyre se debruçando sobre as peculiaridades do caso brasileiro e da colonização portuguesa nos "trópicos".

É possível que a interrogação em torno às supostas simpatias lusotropicalistas de Métraux envolva um falso problema. Ou melhor, não é possível

20 Esta dicotomia com a qual Métraux deve conviver é, em última instância, parte constitutiva da antropologia e das ciências sociais em geral: aquela que transita, tal como assinalam Neiburg e Goldman (1998: 63), entre os extremos da "engenharia social" e da "crítica cultural". 
encarar a solução desse imbróglio sem enfrentar outro problema, desta vez, onipresente: o da observação. Métraux era ciente, muito antes da crítica ao positivismo ingênuo, de que os "fatos" se constroem; e sabia, também, que essa construção dependia de uma delicada relação do observador com seus interlocutores no terreno. Já em 1925, quando a antropologia "acadêmica" na França - e no mundo - dava os seus primeiros passos (Stocking, Jr. 1983, 1989), o jovem Métraux publicava uma reflexão sobre o trabalho etnográfico, cuja lucidez prenuncia uma sensibilidade ímpar. Naquele ensaio, as reminiscências malinowskianas acerca da "magia do etnógrafo" se justapõem ao compromisso de restituir, no processo da pesquisa, uma espécie de ética da política - e da poética, diria Michel Leiris - ao seu justo lugar. Hoje, findos os tremores provocados pela "virada pós-moderna", as palavras de Métraux ecoam com veemente atualidade e clareza:

“... não há método na etnografia; excetuando alguns princípios de prudência e imparcialidade, a liberdade de ação do pesquisador deve ser completa. Nenhuma diretiva preconcebida, nenhum sistema, nenhum questionário deve obstruí-la. Toda sua arte se reduz a uma perpétua adaptação aos homens e às circunstâncias. Apenas o caráter das sociedades nas quais o pesquisador se encontra, bem como a natureza das relações que com elas estabelece devem ditar sua linha de conduta e determinar as condições nas quais serão feitas suas observações, pois o valor dos seus registros depende da sua flexibilidade de espírito e da sua inteligência" (Métraux 1988 [1925]: $71)$.

Na qualidade de "homem de terreno" e ciente da importância da pesquisa empírica e do trabalho de campo - lembremos que ele foi aluno de Marcel Mauss -, Alfred Métraux soube desconfiar das sedutoras insinuações da chamada "democracia racial". Porém, seu lado romântico - e aqui não devemos esquecer, tampouco, seu diálogo com a antropologia "cultural" norte-americana - o fez perseguir as singularidades do Volk. Por tal motivo, Métraux não permaneceu absolutamente indiferente diante da possibilidade de que as "relações raciais" no Brasil operassem no quadro de um ethos e um "caráter nacional" peculiar e irredutível. Cabe aqui nos interrogarmos acerca dessa aparente dicotomia. Será que essas duas dimensões - uma pertencendo à ordem das evidências, outra pertencendo à ordem das aparências - são fatalmente opostas e irreconciliáveis? É possível que, nas próprias indagações de Alfred Métraux, a esfera dos "fatos" (as evidências do preconceito) e a esfera das "representações" (as aparências lusotropicalistas), longe de se repelirem mutuamente, tenham convivido de forma tensa e ambígua. Quiçá essas dimensões tenham operado nos insights interpretativos e nas inquietações empíricas do etnógrafo, não, simplesmente, como duas faces de uma moeda, senão como uma espécie 
de "englobamento dos contrários", ou melhor, como uma relação gestáltica de figura e fundo, na qual as duas dimensões que se apresentam ao campo visual do observador - a "totalidade" - só podem ser apreendidas de forma alternada e nunca simultânea.

\section{BIBLIOGRAFIA}

AAVV, 1999, "Seminário Diários do Campo: Arthur Ramos, os antropólogos e as antropologias", Anais da Biblioteca Nacional, 119: 9-155.

ARAÚJO, Ricardo Benzaquen de, 1994, Guerra e Paz: Casa-Grande \& Senzala e a Obra de Gilberto Freyre nos Anos 30. Rio de Janeiro, Editora 34 Letras.

ARRUDA, Maria Arminda do Nascimento, 1996, "Dilemas do Brasil moderno: a questão racial na obra de Florestan Fernandes”, em M. Chor Maio e R. Ventura (orgs.), Raça, Ciência e Sociedade. Rio de Janeiro, Centro Cultural Banco do Brasil e Editora Fiocruz, 195-203.

BASTIDE, Roger, 1972, Antropología Aplicada. Buenos Aires, Amorrortu Editores.

CLASTRES, Pierre, 1992, "Hommage à Alfred Métraux", em D. Lecoq (org.), Présence d'Alfred Métraux. Paris, Acéphale e Les Amis de Georges Bataille, 29-34.

CLIFFORD, James, 1988, The Predicament of Culture: Twentieth-Century Ethnography, Literature, and Art. Boston, Harvard University Press.

CORRÊA, Mariza, 1988, “Traficantes do excêntrico: os antropólogos no Brasil dos anos 30 aos anos 60", Revista Brasileira de Ciências Sociais, 6 (3): 79-97.

D’ANS, André-Marcel, 1992, "Le contenu d'Itinéraires 2 (1953-1961)”, em D. Lecoq (org.), Présence d'Alfred Métraux. Paris, Acéphale e Les Amis de George Bataille, 5-28.

DEGLER, Carl N., 1976, Nem Preto nem Branco: Escravidão e Relações Raciais no Brasil e nos Estados Unidos. Rio de Janeiro, Edições Labor do Brasil.

DREYFUS, Simone, 1991, "Métraux, Alfred”, em P. Bonte e M. Izard (orgs.), Dictionaire de l'ethnologie et de l'anthropologie. Paris, Presses Universitaires de France, 476-477.

FIGUEIREDO, Érika, Isabela OLIVEIRA, e Janaína DAMASCENO, 2009, “Entrevista com Josildeth Gomes Consorte: os 60 anos do Programa de Pesquisas Sociais do Estado da Bahia e Universidade de Columbia”, Cadernos de Campo, 18: 201-215.

FOSTER, George M., 1969, Applied Anthropology. Boston, Litlle, Brown and Company.

FREYRE, Gilberto, 1940, O Mundo Que o Português Criou. Rio de Janeiro, Livraria José Olympo Editora.

FRIEDMAN, S., 1963, "Alfred Métraux: in memoriam, 1902-1963", International Social Science Journal, XV (2): 167.

GUimarÃeS, Antonio Sérgio, 1996, "Cor, classes e status nos estudos de Pierson, Azevedo e Harris na Bahia: 1940-1960", em M. Chor Maio e R. Ventura Santos (orgs.), Raça, Ciência e Sociedade. Rio de Janeiro, Centro Cultural Banco do Brasil e Editora Fiocruz, 195-203. 
LAURIÈRE, Christine, 2005, “D'une île à l'autre: Alfred Métraux en Haïti”, Gradhiva, 1: 181-207.

LE BOULER, Jean-Pierre, 1994, "Le pied à l'étrier: du bon usage d'une métaphore", em Alfred Métraux e Pierre Verger, Le pied à l'étrier: Correspondance, 1946-1963. Paris, Jean Michel Place, 53-66.

LEIRIS, Michel, 1964, "Hommage a Alfred Métraux", L’Homme, IV (2): 11-15.

MACAGNO, Lorenzo, 1999, "Um antropólogo norte-americano no "mundo que o português criou': relações raciais no Brasil e Moçambique segundo Marvin Harris”, Lusotopie, 1999: 143-161.

MAIO, Marcos Chor, 1997, A História do Projeto UNESCO: Estudos Raciais e Ciências Sociais no Brasil. Rio de Janeiro, Instituto Universitário de Pesquisas do Rio de Janeiro, tese de doutorado.

MAIO, Marcos Chor, 1998, "O Brasil no concerto das nações: a luta contra o racismo nos primórdios da UNESCO”, Manguinhos: História, Ciências, Saúde, V (2): 375-412.

MAIO, Marcos Chor, 1999a, “Tempo controverso: Gilberto Freyre e o projeto UNESCO”, Tempo Social, 11 (1): 111-136.

MAIO, Marcos Chor, 1999b, "O projeto UNESCO e a agenda das ciências sociais no Brasil dos anos 40 e 50”, Revista Brasileira de Ciências Sociais, 14 (41): 141-158.

MÉTRAUX, Alfred, 1929, "Contribution à l'ethnographie et à l'archéologie de la province de Mendoza (Rep. Argentina)", Revista del Instituto de Etnología de la Universidad Nacional de Tucumán, l (1): 5-74.

MÉTRAUX, Alfred, 1941, L’lle de Pâques. Paris, Gallimard.

MÉTRAUX, Alfred, 1942, The Native Tribes of Eastern Bolivia and Western Mato Grosso. Washington, DC, Smithsonian Institution.

MÉTRAUX, Alfred, 1946, Ethnography of the Chaco: Handbook of South American Indians. Washington, DC, Smithsonian Institution.

MÉTRAUX, Alfred, 1949, "Anthropology and the UNESCO pilot project of Marbial (Haiti)", América Indígena, IX (3): 183-194.

MÉTRAUX, Alfred, 1950, "UNESCO and the racial problem”, International Social Science Bulletin, II (3): 384-390.

MÉTRAUX, Alfred, 1951 a, "UNESCO and Anthropology", American Anthropologist, 53 (2): 294-300.

MÉTRAUX, Alfred, 195 lb, “Brazil: land of harmony for all races?”, UNESCO Courier, April: 3. MÉTRAUX, Alfred, 1952, "An inquiry into race relations in Brazil", UNESCO Courier, AugustSeptember: 6-7.

MÉTRAUX, Alfred, 1958, Le Voudou Haitien. Paris, Gallimard.

MÉTRAUX, Alfred, 1963a, "Rencontre avec les ethnologues", Critique, 195-196: 678-684.

MÉTRAUX, Alfred, 1963b, “Se acaba la vida a los 60 años...?”, El Correo, XVI (4): 20-23.

MÉTRAUX, Alfred, 1964, "Entretiens avec Alfred Métraux" (entrevista concedida a Fernande Bing), L'Homme, IV (2): 20-32.

MÉTRAUX, Alfred, 1978, Itinéraires I: Carnets de notes et journaux de voyage. Paris, Payot. MÉTRAUX, Alfred, 1980 [1962], "Victoria Ocampo y la etnología”, Sur, 346: 73-75.

MÉTRAUX, Alfred, 1988 [1925], "De la méthode dans les recherches ethnographiques", Gradhiva, 5: 57-71.

MÉTrAuX, Alfred, e Pierre VERGER, 1994, Le pied à l'étrier: Correspondance, 1946-1963.

Paris, Jean Michel Place. 
MÉTRAUX, Rhoda, 1991, "Métraux, Alfred", em Christopher Winter (org.), International Dictionary of Anthropologists. Nova Iorque e Londres, Garland Publishing, 475-476.

MONNIER, Alain, 2003, Nostalgie du Néolithique: De Lausanne à Las Lomitas, documents sur Alfred Métraux, ethnologue. Genebra, Labor et Fides.

MYRDAL, Gunnar, 1944, An American Dilemma: The Negro Problem and Modern Democracy. Nova Iorque e Londres, Harper \& Brothers, 2 vols.

NEIBURG, Federico, e Marcio GOLDMAN, 1998, "Anthropology and politics in studies of national character", Cultural Anthropology, 13 (1): 56-81.

NOGUEIRA, Oracy, 1955, "Relações raciais entre negros e brancos em São Paulo", Anhembi, XVIII (53): 279-299.

NOGUEIRA, Oracy, 1998, Preconceito de Marca: As Relações Raciais em Itapetininga. São Paulo, Edusp.

OCAMPO, Victoria, 1967, "Carta a Métraux", em Testimonios: Séptima Serie (1962-1967), Buenos Aires, Editorial Sur, 153-156.

PRICE, David H., 2004, Threatening Anthropology: McCarthyism and the FBI's Surveillance of Activist Anhropology. Durham e Londres, Duke University Press.

PRICE, Sally, e Jean JAMIN, 1988, “A conversation with Michel Leiris”, Current Anthropology, 29 (1): 157-173.

STOCKING, Jr., George W., 1983, “The ethnographer's magic: fieldwork in British anthropology from Tylor to Malinowski”, em G.W. Stocking, Jr. (org.), Observers Observed: Essays on Ethnographic Fieldwork. Madison, The University of Wisconsin Press, 70-120.

STOCKING, Jr., George W., 1989, "The ethnographic sensibility of the 1920s and the dualism of the anthropological tradition”, em G. W. Stocking, Jr. (org.), Romantic Motives: Essays on Anthropological Sensibility. Madison, The University of Wisconsin Press, 208-275 .

STOLCKE, Verena, 1998, "Brasil: uma nação vista através da vidraça da raça", Revista de Cultura Brasileña, 1: 207-220.

WAGLEY, Charles, 1964, "Alfred Métraux, 1902-1963", American Anthropologist, 66 (3): 603$-613$. 